\title{
Diálogos de formadores: o ensino e a aprendizagem da dacência no âmbito do pibid geografia
}

\author{
Formation dialogues: teachers' teaching and learning within pibid (geography)
}

\author{
Claudivan Sanches Lopes* \\ Sirlei Aparecida Frabrini Gomes** \\ Raquel Pereira Dias**
}

\section{Resumo:}

Apresentamos, neste trabalho, reflexóes dialógicas de um coordenador do Pibid Geografia da Universidade Estadual de Maringá e de duas supervisoras que acompanham alunos bolsistas em suas atividades de iniciação à docência nas escolas parceiras. Buscamos discutir, entre outras, as seguintes questôes: Que tipo de saber as professoras supervisoras comunicam aos alunos? Que tipo de saber o professor coordenador comunica aos alunos? Como estabelecer o devido diálogo entre esses saberes e aproximar, em prol da formação dos alunos, essas duas instituiçôes que representam? Mostramos, nesse contexto, que o Pibid tem o papel atual e potencial de provocar uma aproximação mais intensa entre a Universidade e a Educação Básica, lançando, oxalá, os alicerces para a construçấo de uma nova cultura para a formação docente e a constituição de comunidades de aprendizagem. Trata-se do encontro de duas instituiçóes com culturas formativas diferenciadas, mas que, cada uma ao seu modo, exercem e podem exercer uma influência marcante na aprendizagem da docência dos alunos envolvidos.

\begin{abstract}
:
The dialogical reflections of a coordinator of the Institutional Scholarship Program for Initiation in Teaching (PIBID) in Geography of the State University of Maringá and two monitors that supervise the activities of two scholarship holders in their teaching activities in partner schools are provided. The following issues are discussed: What type of knowledge the monitor teachers transmit to their students? What type of knowledge the coordinating professor communicates to students? How may one establish the due dialogue between these types of knowledge and approach the two institutions that they represent in the benefit of students' formation? PIBID has a true and potential role of causing a more intense approximation between the University and Basic Education by foregrounding a new culture for teachers' formation and the constitution of learning communities. It is the meeting of two institutions with different formative cultures, each influencing markedly the learning of teaching of the students involved.
\end{abstract}

* Universidade Estadual de Maringá

${ }^{* *}$ Secretaria de Educação do Estado do Paraná
Palavras-chave: Formação de professores de Geografia; Saberes docentes; PIBID.

Keywords:

Formation of Geography teachers; teachers' knowledge; PIBID 


\section{INTRODUÇÁO}

$\mathrm{O}$ Programa Institucional de Bolsa de Iniciação à Docência (Pibid) se caracteriza como uma importante política pública educacional cujo foco central é o aperfeiçoamento do processo formativo e a valorização profissional dos professores para a Educaçáo Básica. Mantido pela Coordenação de Nível Aperfeiçoamento de Nível Superior (Capes), vinculada ao Ministério da Educação (MEC), o Programa se iniciou em 2008 e, na atualidade (2016), mantém, em diversas instituiçóes que abrangem praticamente todo o território nacional expressiva quantidade de bolsas que contemplam, além de alunos matriculados nas licenciaturas, professores supervisores (vinculados à Educação Básica) e professores orientadores (vinculados às universidades) 1 .

$\mathrm{Na}$ Universidade Estadual de Maringá (UEM), o número de alunos bolsistas2 é em torno de 419, e no âmbito do Departamento de Geografia (DGE/UEM), o Programa atende a 32 bolsistas. Estes, em grupo de aproximadamente oito alunos e em diferentes escolas do município, são supervisionados por quatro professores já experientes que compóem o quadro próprio do magistério público do estado do Paraná e, colaborativamente, são coordenados por dois professores vinculados à Universidade.

O Pibid busca, nesse contexto, fomentar a formação dos futuros professores garantindo-lhes, para além daquilo que os próprios currículos das diversas instituiçôes já propiciam, uma presença mais intensa - quantitativa e qualitativa - desses no cotidiano das escolas. Espelha, mais amplamente, as pesquisas e discussões que, no âmbito do movimento pela profissionalizaçáo dos professores têm evidenciado a importância da prática para a futura atividade profissional dos professores (SHULMAN, 2005b; TARDIF, 2006, GAUTHIER, et al. 1998; LOPES, 2010; LOPES e PONTUSCHKA, 2011). Visa, portanto, fomentar os processos de aprendizagem da docência, aproximando-os, ainda mais, do "chão da sala de aula", ou seja, centrado no espaço privilegiado do exercício da docência: a escola.

O Pibid inclui e reúne colaborativamente, além

1 Segundo dados disponibilizados no site da Capes (http://www.capes. gov.br/educacao-basica/capespibid/relatorios-e-dados), o programa oferecia, em 2015, 72.845 bolsas de iniciação à docência. É sabido que esse número foi reduzido. Entretanto, no momento da redação desse texto, náo foram encontrados dados atualizados na Capes.

2 Além das bolsas de Iniciação à Docência (ID) o Programa concede, na UEM, bolsas a 27 coordenadores de área, 57 supervisores (professores da educação básica), 04 bolsas de coordenação de gestão e 1 bolsa de coordenação institucional, totalizando, portanto, 508 bolsistas (dados de 2016). dos próprios alunos bolsistas, os supervisores, professores da Educação Básica e os coordenadores de área, professores ligados às universidades. Desse modo, sua configuração coopera para a valorização de saberes que emergem de diferentes fontes: professores das escolas participantes, professores formadores das universidades e docentes em formação. Entendemos, assim, que Programa tem o papel atual e potencial de provocar uma aproximaçáo mais intensa entre a Universidade e a Educação Básica, lançando, oxalá, os alicerces para a construção de uma nova cultura para a formação docente.

É nesse contexto que se insere os propósitos deste artigo. Considerando que a responsabilidade pela formaçáo dos bolsistas, futuros professores no âmbito do Pibid, é compartilhada por essas duas categorias de formadores, propomo-nos refletir, crítica e coletivamente, sobre essa experiência com o intuito de contribuir para a melhoria desse processo e favorecer o pleno cumprimento de seus objetivos.

Apresentamos, assim, neste texto, as reflexóes dialógicas de um coordenador do Pibid/Geografia/ UEM e de duas supervisoras que acompanham os bolsistas em suas atividades nas escolas conveniadas. Trata-se, portanto, do encontro de duas instituiçóes com culturas formativas diferenciadas, mas que, cada uma ao seu modo, exerce e pode exercer uma influência marcante na aprendizagem da docência dos alunos envolvidos. Temos por pressuposto, por conseguinte, que os professores supervisores, para além de simplesmente receber estagiários e, nesse caso, alunos bolsistas do Pibid/Geografia/UEM, podem comunicar um saber que é fundamental à formação dos alunos. São, de fato, formadores de professores.

Entretanto, algumas questôes se nos apresentam: Que tipo de saber as professoras supervisoras comunicam aos alunos? Que tipo de saber o professor coordenador comunica aos alunos? Como estabelecer o devido diálogo entre esses saberes? Como aproximar, em prol da formação dos alunos, essas duas instituiçôes que representam? Quais as diferenças culturais identificadas ao longo do processo? Que obstáculos foram identificados? Qual o impacto do Pibid na formaçáo dos alunos bolsistas? Qual a importância do Pibid para o processo de formaçáo continuada dos próprios formadores envolvidos no processo - supervisoras e coordenador? São essas as perguntas que apresentamos e que, nos limites deste artigo, buscamos responder.

Metodologicamente, o artigo foi construído com o respaldo dos referenciais bibliográficos selecionados pelo Pibid Geografia da UEM a partir da realização de 
sessóes de reflexão coletiva e crítica sobre as atividades desenvolvidas ao longo do ano de 2014 e de 2015. Assim, estruturamos este texto em três partes. Em um primeiro momento, apresentamos algumas consideraçóes teóricas relativas à formação de professores nas quais se ancoram nossas reflexões; em um segundo momento, apresentamos sobre as reflexóes das duas professoras supervisoras e, no terceiro momento, apresentamos as reflexôes do professor coordenador. Nas consideraçóes finais, buscamos sintetizar as reflexôes e o "esforço dialógico" a que nos propomos, neste artigo, realizar.

\section{A APRENDIZAGEM DA DOCÊNCIA E AS CONTRIBUIÇÓES DA PESQUISA SOBRE OS SABERES DA DOCÊNCIA}

O surgimento e o desenvolvimento dos estudos referentes aos saberes da docência (SHULMAN, 2005a; 2005b; TARDIF, 2006; GAUTHIER et al., 1996; LOPES, 2010; LOPES e PONTUSCHKA, 2011) têm apontado para a necessidade de se considerar a prática pedagógica do professor no contexto escolar como lócus privilegiado da construção e mobilização de saberes profissionais. Negando o papel tradicional de simples reprodutor de conhecimentos produzidos por peritos ou especialistas, o professor passa a ser (re)valorizado como protagonista do trabalho escolar. Adquire, portanto, potencial centralidade no desenvolvimento do currículo e na implementação das políticas educativas. Dessa maneira, a relação tradicional entre a universidade - lugar da produçáo da teoria e do conhecimento - e a escola básica - lugar de reprodução e/ou aplicação de teorias e conhecimentos - é fortemente criticada e se busca, nessa perspectiva, uma aproximação colaborativa entre as duas instituiçôes (LOPES; PONTUSCHKA, 2011).

A perspectiva que se descortina corrobora a ideia de que, paralelamente à busca de conhecimentos para o ensino externamente à profissão, é fundamental identificar os conhecimentos produzidos no ensino, ou seja, os conhecimentos produzidos pelos professores em seu contexto sempre complexo de trabalho. Os ventos que sopram da academia sempre são bem-vindos, entretanto estes não são os únicos "motores" que podem fazer mover e desenvolver a profissão. A força da profissão deve brotar, fundamentalmente, do seu interior, pelo estabelecimento de uma comunidade profissional consciente de seu papel no ensino. Ou seja, a perspectiva de análise que subjaz a esse texto conduz à compreensão dos saberes docentes como componentes nucleares de sua profissionalidade. Defendemos, portanto, que o repertório de conhecimentos profissionais mobilizados pelo professor em seu trabalho é composto tanto por aqueles conhecimentos elaborados por investigadores especializados nas diversas áreas afins à educação e à disciplina que ministra como por aqueles conhecimentos elaborados, individual ou coletivamente, pelos próprios professores no processo de reflexáo sobre suas práticas.

Compreendemos, dessa forma, que as teorias do saber docente têm como um de seus axiomas a negação categórica de a capacidade de modelos tecnocráticos orientarem a formação e a prática profissional docente. Ou como assinala Monteiro (2001), representa a tentativa de superar a relaçáo linear e mecânica entre o conhecimento técnico-científico e a prática na sala de aula. Foram, continua a autora, "[...] os limites e as insuficiências dessa concepção [que] levaram à busca de novos instrumentos teóricos que fossem capazes de dar conta da complexidade dos fenômenos e açóes que se desenvolvem durante atividades práticas". Assim, "[...] no bojo desses estudos, foi criada a categoria saber docente que busca dar conta da complexidade e especificidade do saber constituído no (e para o) exercício da atividade docente e da profissão [...]" (p. 130, grifos da autora). Destarte, o professor deixa de ser visto como simples consumidor do conhecimento gerado pela investigação científica.

O reconhecimento de que os professores produzem saberes e a reivindicação de um novo estatuto ao saber que emerge cotidianamente na prática redimensiona e (re) valoriza o trabalho dos professores supervisores de estágio e, em consequência, os professores supervisores no âmbito do Pibid.

Esse profissional, como sabemos, tem um contato prolongado com o estagiário e as pesquisas mostram sua influência sobre a formação dos futuros professores. Como afirmam Pimentel e Pontuschka (2011, p. 1):

É evidente a importância desse professor na formaçáo inicial
dos alunos da licenciatura em períodos de estágio. Contudo
essa importância não remete à mera presença desse sujeito, mas
a uma participação ativa dele no decurso da formaçáo desses
alunos. Alguns saberes de base para a docência são gerados na
práxis profissional, nela se expressam e se reconstroem, revelan-
do a validade da observaçáo e participaçáo dos estagiários no
lócus de ensino. Podemos citar como exemplo o conhecimento
pedagógico do conteúdo, descrito por Shulman (2005a), que é
construído pelo professor a partir de referenciais teórico-práti-
cos utilizados em suas experiências ao ensinar.

Como muito bem observam Pimentel e Pontuschka (2011), ainda que normalmente as instituiçóes de ensino da educaçáo básica tenham acordos formais com as instituiçóes universitárias, o trabalho com estagiários não faz parte da funçấo docente do professor da escola 
básica e, por isso, como sabemos, ainda é considerado um trabalho voluntário. Considerando as experiências descritas por Zeichner (1995) nos Estados Unidos, as autoras assinalam que a escola básica toma essa tarefa de formar o professor - como secundária em relação ao objetivo da formação dos alunos de nível fundamental e médio. Desse modo, concluem: "Nossa experiência permite dizer que ocorre o mesmo no Brasil. Neste caso, acreditamos que, para obtermos melhores resultados na formaçáo inicial dos alunos da licenciatura em períodos de estágio é necessário permissão e desejo por parte dos professores da escola básica" (PIMENTEL; PONTUSCHKA p. 3).

Como sustentam Jackson (2001) e Sacristán (1995) e com eles concordam outros pesquisadores, os professores sáo um tipo de pessoas que falam pouco do seu ofício entre si e de como o melhorar, que transmitem pouco a sua experiência profissional. Nesse sentido, a ação e o contato mais prolongado dos professores supervisores como, por exemplo, as que ocorrem no âmbito das atividades do Pibid Geografia da UEM poderiam estimular os professores, individual e coletivamente, a compartilharem mais suas experiências na profissão, formando, assim, comunidades de aprendizagem, ou seja, "[...] um grupo de professores [e de futuros professores] no qual exista um engajamento com a aprendizagem dos alunos e, também, com o desenvolvimento profissional de todo o grupo por meio de uma atitude constante de estudo e reflexão sobre os conteúdos de ensino" (GUERTA; CAMARGO, 2015, p. 609).

\section{O SABER DA EXPERIÊNCIA: AS REFLE- XÓES DAS SUPERVISORAS ${ }^{3}$}

Ousamos, ao longo de nossa carreira, aprender e incorporar, paralelamente à tarefa precípua de ministrar aulas, outros papéis e funçóes à nossa prática profissional. A partir de nossa experiência como professoras da Educação Básica do Estado do Paraná há mais de 20 anos, formadas pela própria Universidade Estadual de Maringá, buscamos manter e estreitar as relaçóes como essa instituição, primeiramente pelo acolhimento de estagiários dela provindos por acreditar que podemos contribuir para a formação acadêmica desses alunos que, em breve, iniciarão sua jornada profissional no ensino. Fazer parte do Pibid como supervisoras significa, dessa maneira, o reconhecimento da qualidade de nossos anos de profissionalização.

Consideramos que as atividades desenvolvidas no âmbito do Pibid vêm ao encontro dos anseios profis3 Considerando os objetivos deste artigo, o estilo de redação das professoras supervisoras foi mantido. sionais dos licenciandos, pois estendendo-se ao longo de todo ano letivo, vão para além do estágio curricular obrigatório, normalmente de curta duração. Temos observado, nesse sentido, o crescimento teórico e prático dos sujeitos envolvidos no Programa, tanto por parte do graduando quanto para nós como supervisoras. $\mathrm{O}$ trabalho coletivo, centrado em contínua discussão e na socialização de conhecimentos, constitui-se em um momento privilegiado de formação que nos impulsiona a prosseguir e auxiliar na construção do perfil pedagógico de cada um dos bolsistas, estimulando-os a serem sujeitos reflexivos em sua própria formação profissional.

Nós professores, no exercício de nossas funçóes e no desenvolvimento cotidiano das práticas da profissão, construímos e reconstruímos saberes que, ao longo da vida, foram sendo acumulados e revisados, isto é, saberes experienciais (TARDIF, 2006). É nesse contexto que justificamos nossa participação como colaboradoras na formação profissional dos graduandos, articulando a comunicação entre saberes acadêmicos - adquiridos na universidade - e saberes práticos - aqueles oriundos da prática profissional.

Segundo Tardif (2006), os saberes docentes são elementos plurais constitutivos da prática profissional dos professores. São formados por saberes pedagógicos (concepçóes teórico-metodológicas), saberes disciplinares (conhecimento adquirido ao longo da jornada acadêmica), saberes curriculares (conteúdos e métodos que formam o programa escolar) e ainda saberes profissionais (adquiridos ao longo da profissionalização) incorporados à prática como saberes experienciais ou práticos. Na visão do autor,

[...] o professor ideal é alguém que deve conhecer sua matéria, sua disciplina e seu programa, além de possuir certos conhecimentos relativos às ciências da educação e à pedagogia e desenvolver um saber prático baseado em sua experiência cotidiana com os alunos. Essas múltiplas articulaçóes entre a prática docente e os saberes fazem dos professores um grupo social e profissional cuja existência depende, em grande parte, de sua capacidade de dominar, integrar e mobilizar tais saberes enquanto condição para sua prática (TARDIF, 2006, p. 39).

$\mathrm{Na}$ comunicação estabelecida entre escola e universidade, notamos o crescimento dos saberes profissionais perceptíveis ao longo da trajetória desenvolvida, em que a maturidade profissional é estimulada, fazendo com que os iniciantes reflitam sobre as situaçóes reais, troquem informaçóes e posteriormente discutam fatos e açóes que presenciam, despertando e fortalecendo principalmente a construção colaborativa do perfil profissional de cada um dos envolvidos (bolsistas, supervisoras e coordenadores). Cremos, assim, que o fato de 
estarem presentes em meio às diversas situaçóes que o ambiente escolar proporciona é mais uma oportunidade de fomentar a formação inicial do bolsista, pois in loco vivenciam e experimentam a prática pedagógica docente na sua integralidade.

Consideramos que entre os saberes docentes apontados por Tardif (2006) o "saber experiencial” é o diferencial que marca nosso trabalho, pois está relacionado à prática do professor em sala de aula. Tal saber se expressa na capacidade de refletir, criar e inovar em situaçóes de aula e revela características próprias de sua profissionalidade. Trata-se, pois, de perceber nas experiências com o educando a oportunidade de aprender. $\mathrm{Ou}$ seja, os professores, em sua prática diária, desenvolvem formas e mecanismos próprios de exercer seu ofício, que combinados ao domínio de conteúdo, organização do espaço da sala de aula, atitudes contagiantes e "brilho no olhar", proporcionam e abrem a possibilidade de instituir "ambientes" diferenciados de aprendizagem.

Nesse contexto, em muitos momentos permitimos que a sala de aula seja transformada em laboratório, onde os alunos são instigados, provocados e desafiados, objetivando um processo de construção de conhecimentos que muitas vezes o livro didático não aborda. Verificamos, assim, em algumas situações, que o uso dos manuais didáticos são minimizados, pois o saber experiencial nos assegura conhecimentos já adquiridos e por nós mesmos validados. Usamos também de certa dose de dinamismo para abordar temas múltiplos, e o exemplo é o próprio aluno em seu contexto social. Ao perseguir o objetivo de ensinar, lançamos mão de mecanismos profissionais como variação do tom de voz, expressão corporal e facial, dramatização, mapas conceituais, entre outros, que nos é original enquanto educadoras.

Nessa perspectiva, temos proporcionado aos graduandos, bolsistas do Pibid vivenciar e experienciar situaçóes concretas de ensino-aprendizagem, possibilitando o desenvolvimento e o fortalecendo o perfil profissional do futuro professor. $\mathrm{O}$ que nos tem chamado a atenção é a dedicação e, muitas vezes, até certo "encantamento" do bolsista em poder experimentar o "outro lado", superando ou realizando a passagem da condição de discente (ainda graduando) para, efetivamente, atuar como docente (professor).

Temos, a partir dos muitos encontros realizados, possibilitado aos acadêmicos a emersão do saber profissional que os auxiliarão a serem profissionais comprometidos com a aprendizagem de seus discentes. Durante o ano letivo, proporcionamos aos bolsistas vivenciarem a prática da escola e da sala de aula por meio de observa- ções, produçóes e implementações de recursos didáticos, e mediaçóes. Nesse período, foi-nos possível perceber na conduta dos graduandos de Geografia uma mudança de postura, pois a priori demonstravam atitudes muito próximas às dos discentes com quem se relacionavam. $\mathrm{O}$ amadurecimento das atitudes dos graduandos só se efetivou mediante envolvimento significativo nas atividades propostas nas escolas de atuação, bem como no contato com os alunos dentro de sala de aula.

Dentre as atividades oportunizadas aos bolsistas no contexto escolar durante todo o ano letivo de 2014 e parte de 2015, identificamos e presenciamos a vivência do cotidiano escolar que inclui seu ritmo, horários, ocupação dos espaços, trabalho realizado por todos os profissionais da educação, o encaminhamento de soluçóes, ações que resultam em melhoria do trabalho pedagógico, além de todas as mazelas encontradas no âmbito educacional. Destas, podemos destacar o "confronto" entre alunos e professores, conflitos entre os próprios alunos, o excesso de ruídos no horário do recreio, espaços inadequados e pequenos ou a falta deles, conflitos entre profissionais da educação, entre outros.

Deste modo, o contato com o "verdadeiro ambiente escolar" durante todo o ano letivo proporcionou aos graduandos pertencentes ao Programa vivenciarem e experienciarem o dia-a-dia e adquirirem conhecimentos sobre todo o contexto escolar e principalmente conhecer a rotina pedagógica que envolve a Educação Básica. Nossas práticas profissionais passam, agora, não só pela atuação no magistério como professores que ensinam conhecimentos geográficos a seus alunos, mas também como colaboradoras na formação dos graduandos que vivem essa experiência na escola na busca de se tornarem profissionais comprometidos com a educação.

Acreditamos que ao se envolverem diretamente com o fazer pedagógico no âmbito escolar, as capacidades de observação, de discussão e de vivência dos acadêmicos passam a ser ampliadas, fortalecendo e estimulando conhecimentos para a vida profissional dos iniciantes, o que vem ao encontro dos objetivos do Pibid, que é a participação efetiva e cotidiana em atividades educativas, e, assim, ampliando sua formação e qualificação para o exercício da docência.

A supervisão de ensino oferecida pelo Pibid possibilita, também, o retorno das docentes supervisoras à universidade. Essa parceria tem possibilitado a expansão de diversos saberes por meio de estudos e discussóes acadêmicas, contribuindo para o aperfeiçoamento e atualização de nossa qualificação profissional com a finalidade de suprir demandas da função tanto como docentes 
como supervisoras de alunos, futuros professores em processo de formação.

Por fim, outro ponto a salientarmos como supervisoras do Pibid é justamente a oportunidade de formalizarmos os conhecimentos adquiridos nas diversas práticas realizadas em vários programas e projetos dos quais temos participado efetivamente ao longo de nossa jornada em busca de melhoria e expansão dos domínios profissionais. Como professoras do Ensino Fundamental e Médio, nos envolvemos e nos concentramos de tal forma em nossas atividades diárias junto ao ambiente escolar, que inclui a prática em sala de aula e tarefas burocráticas próprias do exercício da docência, que não nos é possível, muitas vezes, ampliar nossos horizontes, escrevendo e publicando nossas experiências. Destacamos, assim, a importância do Pibid como espaço para teorizarmos criticamente nossas práticas.

\section{O SABER DA ACADEMIA: AS REFLEXÓES DO COORDENADOR}

Consideramos, como já apontamos neste artigo, que a responsabilidade pela formação dos alunos bolsistas no âmbito do Pibid é compartilhada tanto por nós professores coordenadores vinculados às universidades como pelos professores supervisores vinculados à Educaçáo Básica. Temos por pressuposto, portanto, que o Pibid é um momento importante de encontro entre formadores, a saber, coordenadores e supervisores que representam, respectivamente, o saber proveniente das pesquisas que proveem especialmente dos programas de pós-graduação e o saber experiencial (TARDIF, 2006) ou a sabedoria prática (SHULMAN, 2005b) que brota sobretudo do próprio exercício profissional dos professores.

Entendemos, desse modo, que a efetividade e a qualidade desse processo formativo decorrem do mútuo conhecimento e reconhecimento dos saberes que cada categoria de formadores comporta e das características do diálogo possível de ser estabelecido entre ambos, tendo em vista a promoção da aprendizagem da docência pelos alunos bolsistas. É preciso, portanto, que não sejam estabelecidas hierarquias: o saber prático não é de qualidade inferior ao teórico.

Os futuros professores têm, nessa perspectiva, a possibilidade de refletirem criticamente sobre a histórica dicotomia existente entre os saberes acadêmicos, construídos prioritariamente nos espaços de formação universitários e os saberes experienciais, construídos no espaço de atuaçáo profissional dos professores. Podem eles, reflexivamente, verificarem que os professores pro- duzem sim saberes diversos no âmbito da prática e que, sem rejeitar os contributos teóricos que provêm da pesquisa científica na área, "[...] não há melhor lugar para aprender a ser professor do que o próprio espaço da sala de aula”. (LIMA, 2013, p. 139).

Trata-se de compreender, como afirma Sacristán (1995), que a teoria não pode inventar a prática, mas que, ao mesmo tempo, o "ateoricismo" é uma postura incompatível com os desejos de emancipação profissional dos professores e mesmo um empecilho para a compreensão mais profunda do fenômeno educativo institucionalizado. Náo buscamos, nessa perspectiva, apenas observar ou "coletar" boas práticas pedagógicas de bons professores. Antes de tudo, trata-se de possibilitar ao futuro professor a apropriaçáo e o desenvolvimento de um repertório teórico prático que lhe permita superar tanto o "praticismo" como o "teoricismo". Significa perceber os limites da teoria na invenção da prática e, simultaneamente, os perigos do praticismo acrítico. Se o desenvolvimento das práticas educativas pelos professores em sala de aula, como pontua Jackson (2001), evidenciando sua complexidade e impossibilidade de ser guiada por uma racionalidade técnica, se parece mais com o voo de uma borboleta que com a trajetória de uma bala, é preciso acrescentar que tal complexidade não significa a renúncia ao necessário esforço de compreensão teórica que esse processo exige.

Pontuamos, dessa maneira, que a presença mais contínua dos alunos bolsistas no ambiente escolar lhes permite compreenderem a escola de modo geral e, particularmente, a sala de aula de Geografia como espaços complexos. Podem verificar, assim, que as possibilidades de ação são diversificadas e os caminhos percorridos pelos docentes para encontrarem soluçóes para os problemas que enfrentam carregam as marcas de sua subjetividade: o "saber experiencial" destacado neste trabalho é, em grande medida, biográfico, ou seja, reflete características da personalidade de quem os produziu.

Nesse sentido, temos a convicção de que o Pibid, à semelhança dos estágios supervisionados, é uma ocasião privilegiada de reflexão sobre o processo de "aprender a ensinar". Para além da aquisiçáo dos saberes para ensinar, os alunos bolsistas podem iniciar o processo de construção de seu "perfil pedagógico" ou sua "personalidade pedagógica" que, evidentemente, estará sujeito a um contínuo processo de revisão e redefiniçôes. Trata-se de um momento importante para firmar, coletiva e individualmente, a identidade do profissional docente.

Se o processo descrito no parágrafo anterior vale para os futuros professores, vale também, certamente, 
para as professoras supervisoras e para o professor coordenador. As primeiras, porque, como elas próprias destacam, as diversas situaçóes vivenciadas no Programa proporcionam "o aperfeiçoamento e atualização de nossa qualificação profissional” e, para este último, como buscamos aprofundar a seguir, porque permite repensar práticas e metodologias relacionadas à formação do professor.

Entendemos, considerando as funçóes próprias do coordenador, que essas experiências nos permitem refletir sobre os processos de construçáo dos saberes docentes e os modos mais concretos - estratégias e práticas - de apropriação pelos alunos bolsitas. Trata-se uma oportunidade de rever metodologias e encontrar caminhos alternativos para comunicar os conhecimentos de base para o exercício da docência. O Pibid pode ser, por conseguinte, além de um campo de extensão e ensino, um campo privilegiado de observação e de investigação para o coordenador. Junto aos alunos e supervisoras este tem a oportunidade pensar ou repensar suas funçóes e responsabilidades nesse processo formativo.

Outro aspecto importante a ser ressaltado nas estratégias do Pibid é a experiência acumulada por todos os participantes no trabalho em equipe e a possibilidade da vivência dialógica dos problemas identificados e a busca de resoluçáo dos mesmos.

Embora na estrutura administrativa do Pibid os professores coordenadores tenham uma ascendência sobre os professores supervisores, a relação com estes supôe, de nosso ponto de vista, uma organização não hierárquica na qual, tendo em vista a melhor formação possível para os bolsistas, ocorra um mútuo reconhecimento dos saberes, que, como já evidenciamos, cada um é portador. Isso exige, destarte, um forte comprometimento ético de todos os envolvidos no processo e uma postura aberta e cultivadora do diálogo. Do contrário, um clima de competição ou de mera contraposiçáo de conhecimentos e de posturas poderia desvirtuar a riqueza que o Pibid proporciona aos seus protagonistas.

\section{CONSIDERAÇÓESS FINAIS}

As pesquisas que focam os saberes docentes evidenciadas neste trabalho têm mostrado com bastante vigor e propriedade a necessidade de repensar a formação de professores levando em conta os saberes específicos dos professores e as reais condiçôes de realização de seu trabalho cotidiano. Entendemos, assim, que a implantação do Pibid representa uma importante contribuição ao processo formativo e, mais amplamente, à valorização dos profissionais da educação em nosso país, por- que, considerando as características neste trabalho descritas, possibilitam aos futuros professores um contato mais intenso com o cotidiano escolar e com os saberes da profissão, entre os quais os "saberes da experiência" comunicados pelas supervisoras têm um papel destacado. Como vimos ao longo deste trabalho, os professores supervisores valorizam esse tipo de saber e a pesquisa acadêmica, notadamente aquela denominada "saberes da docência", tem contribuído para promovê-la e legitimá-la.

Constitui-se, portanto, de nosso ponto de vista, em uma política de formação de professores que, se não interrompida trará, sem dúvida, forte impacto no processo de formação e na profissão docente como um todo. Assim, tal Programa se insere no campo das políticas que expressam a vontade de estabelecer, nos cursos de formação de professores, "[...] uma nova articulação e um novo equilíbrio entre os conhecimentos produzidos pelas universidades a respeito do ensino e os saberes desenvolvidos pelos professores em suas práticas cotidianas" (Tardif, 2006, p. 23, grifos do autor). O aluno bolsista pode, nesse contexto, como salientamos ao longo deste artigo, contrapor reflexivamente diferentes saberes - notadamente saberes acadêmicos e saberes experienciais - e, em um momento de diálogo e aproximação salutar entre as duas instituiçóes, realizar sua própria síntese.

Verificamos que os obstáculos encontrados no processo formativo do Programa relacionam-se, entre outras, às dificuldades que os iniciantes apresentam em escrever sínteses dos trabalhos realizados, na organização estrutural dos textos produzidos e, de modo associado, à falta de tempo da professora supervisora, já que as demandas se estendem para além das horas previstas. Como sabemos, a jornada de trabalho dos professores da Educação Básica se alarga para além da sala de aula, e pontuamos, também, os muitos compromissos que os bolsistas assumem no desenvolvimento das demais atividades referentes à graduação. É preciso assinalar ainda que os bolsistas, considerando seu estágio de formação $\left(1^{\circ}, 2^{\circ} 3^{\circ}\right.$ e $4^{\circ}$ anos), trazem consigo diferentes bagagens intelectuais. Tal realidade, evidentemente, também comporta elementos positivos, entretanto requer dos supervisores e dos coordenadores um olhar atento à dinâmica do trabalho para não "queimar etapas" na formação de uns, por um lado, e do outro, subestimar as potencialidades dos alunos dos anos finais da graduação.

Entretanto, nenhum dos condicionantes negativos identificados nesse decurso são suficientes para provocar desânimo nos protagonistas do trabalho formativo aqui descrito e analisado. De nosso ponto de vista, o 
Pibid tem se apresentado como um processo de crescimento individual e coletivo que aponta para a constituição de comunidades de aprendizagens (GUERTA; CAMARGO, 2015; SULMAN, 2004) nas quais diferentes sujeitos produzem e comunicam, como vimos, múltiplos saberes. Aprendem os alunos bolsitas sobre os saberes de base da docência em Geografia, aprendem as supervisoras a transmitirem conhecimentos práticos que possuem aos bolsistas e aprendem os coordenadores à medida que podem repensar, para além das práticas desenvolvidas no Pibid, as estratégias para a formação de professores.

\section{REFERÊNCIAS}

GAUTHIER, C. et al. Por uma teoria da pedagogia: pesquisas contemporâneas sobre o saber docente. Ijuí, RS: Unijuí, 1998.

GUERTA, R. S.; CAMARGO, C. C. Comunidade de aprendizagem da docência em estágio curricular obrigatório: aprendizagens evidenciadas pelos licenciandos. Ciênc. Educ., Bauru, v. 21, n. 3, p. 605-621, 2015. Disponível em: $<$ http://www.scielo.br/pdf/ciedu/v21n3/1516-7313-ciedu-21-03-0605.pdff Acesso em: 16 de nov. 2015.

JACKSON, Ph. W. La vida en las aulas. 6. ed. Madrid (Espanha): Morata/Paideia, 2001.

LIMA, A. C. R. E. Caminhos da aprendizagem da docência: os dilemas profissionais dos professores iniciantes. In: VEIGA, I. P. A.; D’AVILA, C. (Orgs.). Profissão docente: novos sentidos, novas perspectivas. 2. ed. Papirus: Campinas, SP, p. 135-150, 2013.

LOPES, C. S. O professor de Geografia e os saberes profissionais: o processo formativo e o desenvolvimento da profissionalidade. 2010. 258 p. Tese (Doutorado) - Faculdade de Filosofia, Letras e Ciências Humanas, Universidade de São Paulo, São Paulo.

LOPES, C. S.; PONTUSCHKA, N. N. Mobilizaçáo e construção de saberes na prática pedagógica do professor de Geografia. Geosaberes, Fortaleza, v. 2, n.3, p. 89-104, 2011. Disponível em: <http://www.geosaberes.ufc.br/seer/ index.php/geosaberes/article/viewFile/89/pdf38>. Acesso em: 05 Jan. 2015.

MARCELO, C. Pesquisa sobre a formação de professores: o conhecimento sobre aprender a ensinar. Revista Brasileira de Educação. São Paulo, n. 9, p. 51-75, dez.1998.

MONTEIRO, A. M. F. C. Professores: entre práticas e saberes. Educação e Sociedade. Campinas, Cedes, v. 22, n. 74, p. 121-142, 2001.

PIMENTEL, C. S., PONTUSCHKA, N. Representações sobre o estágio na formaçáo inicial de professores de Geografia. Olhar de Professor, Ponta Grossa, v. 13, n. 1, p. 67-87, 2011. Disponível em: http://www.revistas2.uepg. br/index.php/olhardeprofessor/article/view/3193. Acesso em: 01 de mai. 2015.

SACRISTÁN, J. G. Consciência e acção sobre a prática como libertação profissional dos professores. In: NÓVOA, A. (Org.). Profissão professor. Porto (Portugal): Porto, 1995. p. 63-92.

SHULMAN, L. S. El saber y entender de la profesión docente. Estúdios Públicos, SanOsmar-Chile, n. 99, p. 195224, 2005 a.

SHULMAN, L. S. Conocimiento y enseñanza: fundamentos de la nueva reforma. Profesorado. Revista de Currículum y Formación del Profesorado Granada-España, v. 9, n. 2, p. 1-30, 2005b. Disponível em: <http://www.ugr.es/ recfpro/ rev92ART1.pdf $>$. Acesso em: 27 de out. 2017.

SHULMAN, L. S. Teaching as community property: essays on higher education. Hutchings, P. (Ed.). San Francisco (Estados Unidos): Jossey-Bass, 2004.

TARDIF, M. Saberes docentes e formação profissional. 6. ed. Petrópolis, RJ: Vozes, 2006.

ZEICHNER, K. Novos caminhos para o praticum: uma perspectiva para os anos 90. In: NOVOA, A. (Org.). Os professores e a sua formaçáo. 2. ed. Lisboa (Portugal): $\mathrm{Pu}$ blicações Dom Quixote, 1995, p. 115-138.

\section{Correspondência do autor:}

\author{
Claudivan Sanches Lopes 1 \\ cslopes@uem.br \\ Sirlei Aparecida Frabrini Gomes \\ sirleigeo@hotmail.com \\ Raquel Pereira Dias \\ raquel.dias@escola.pr.gov.br
}

\section{ARTIGO RECEBIDO EM: 29/09/2016}

REVISADO PELO AUTOR EM: 26/10/2017

ACEITO PARA PUBLICAÇÁO EM: 26/10/2017 